\title{
THE SUMMARY OF “STRATEGI IMPLEMENTASI KNOWLEDGE MANAGEMENT"
}

Sunarti - Doctoral Science in Management - ITB

Rony Sandra Yofa Zebua - Magister of Islamic Education - UNISBA

The book of "Strategi Implementasi Knowledge Management" written by Prof. Dr. Jann Hidajat Tjakraatmadja and Didin Kristinawati, S.T., M.Sc. Dr (cand.) tells all about Knowledge Management (KM). It is started from the discussion related to the reason why KM is important. And then the writers tell about the characteristic of the KM including the terminology of the knowledge itself, KM and also the goal of the KM. The next chapters contain respectively the paradigm and the principle of KM, the framework of KM from 4 types of models, how to measure organizational readiness on implementing $\mathrm{KM}$, the process of $\mathrm{KM}$ and the last chapter says about the strategy to implement KM including the steps of the process and the formula of the process of KM implementation strategy.

\section{Why Knowledge Management (KM) is important?}

History shows that Knowledge management is very important to be applied if people want to be able to adapt to era development. There are some many proofs that showed when people or an organization is incapable of adaptation to change era, they will be left behind or even get bankrupt. The ability to adaptation to the change era is not only applicable to an individual, but also an organization and even a country. The writers gave an example to describe this with the tragedy of monetary crisis happened in Indonesia in 1998 - 1999. The key is, when a country count on mainly to natural resource, it will be limited to certain era. But if the baseline of a country is based on knowledge, it will be last longer. Why? It is because knowledge is growing up so fast. Even the growth can reach five times within four years. It can be imagined when somebody is too lazy to study for example for one year, it means he or she has out of dated knowledge as much as $5 / 4$ of the recent knowledge.

Considering that individual as one of the unit of analysis of $\mathrm{KM}$ has a very wonderful potential (which has mind (akal) and value (aka)), it is a kind of precious asset that should be managed well. Moreover, our brain has capacity up to 100 billion neurons. In addition, human has a common habit: easy to forget something. The paradox that knowledge is growing fast while human is easy to forget something makes it to be very crucial to manage the personal knowledge in order to keep their knowledge sustainable and renewable. The system to manage it is called Personal KM (PKM).

When applying KM in a unit of an organization, the consideration is upon the true role of the employee in the organization in which they are considered as human capital instead of human liability. It means increasing the quality of the employee is not burdening the company but, instead it is kind of investment. The implication of this is that an organization should more focus to enhance the competencies of the employees instead of adding the capital. An 
organization with a high level competency and knowledge will be able to make innovation and organization work development and they will be able to survive in this digital and technology era.

The writers put Indonesia as an example of an organization or a country that puts natural resource as the machine of the economic development. From the data, it showed how slow the economic growth in Indonesia even though this country is rich of natural resource. The GDP is so low due to low knowledge economy. When economy is low, it leads environmental damage. As comparison, it is given the data about some countries which have fast economic growth that turns out that they count on human capital as the machine of the economic development. Nevertheless, Indonesia is able to improve the condition by a strategy to combine knowledgebased economic growth and natural resource-based economy because Indonesia is rich of natural resource. In that way, it is important to measure sustainable growth by using these three index parameters: KEI (knowledge Economy Index, GDP and EPI (environmental Performance Index) and the national economic growth by using EPI and GINI (the measurement of income difference between low income and high income citizen) parameters.

\section{The characteristic of the KM}

The definition of knowledge and $\mathrm{KM}$ is not fixed yet. There is no common definition that is able to be suitable for every context. However, it can be seen the characteristic based on various perception of knowledge and KM from the experts. Based on three definitions from Peter F Drucker, Ikujiro Nonaka and Karl-Erik Sveiby there are 2 keywords to build definition of knowledge: capacity to act and capacity or capability for more effective action. Nonaka categorizes knowledge to be two types: tacit (a conceptual or theoretical knowledge) and explicit (knowledge applied in SOP or documentation).

Knowledge is actually built from data which is changed to be information (meaningful data). in further development, the knowledge turn to be wisdom (deep understanding on a certain phenomenon) and innovation in order to create value. When processing data to be information, computer or data analysis technique. But, the process needs knowledge workers to change the information to be knowledge and innovation.

The definition of Knowledge Management (KM) is also not fixed yet. There are so many versions of definition given by various opinions from experts. From those all definitions, there are 6 common patterns of the meaning of KM: a discipline of individual, team and turn to be an organization to manage knowledge, a management tool to result innovation, to ease process knowledge sharing, to enrich use replication, to manage knowledge workers and to facilitate creative, imaginative and inventive process.

The process of KM basically involves 5 basic processes: knowledge mapping, knowledge storing, knowledge sharing, knowledge applying and knowledge creating. Those all activities are applied into KM activities. 
The primary purpose of KM is actually creating value from three steps: knowledge how, business or work process, work capacity in order to create valuable result. From Kaplan and Norton (2004), there are 4 principles related to creating value: creating value is not happening directly, the value is contextual, the value is potential and the value is from integrated capital.

\section{The paradigm and the principle of KM}

There are at least 30 paradigm shifts related to $\mathrm{KM}$ in order to understand $\mathrm{KM}$. 1) Anything can cause regular value is called capital, 2) unlike physical capital, human capital is appreciated when being used, 3) structural capital can be stolen, but human capital cannot be replicated, 4) most organizational knowledge is still tacit, and explicit is the type of knowledge which is able to be managed better, 5) healthy organization has more intangible asset than tangible asset, 6) learning is personal discipline and responsibility, 7) corporate or company will be deceased if it is not able to learn, 8) learning by doing is more effective than learning in a class, 9) learning how to unlearn is important to improve an organization's life potential inn knowledge era, 10) EQ is more important than IQ to reach success in working and or business, 11) knowledge creates value when sharing and being used, 12) knowledge is higher octan information, 13) tacit knowledge is the highest level of knowledge, 14) knowledge network can create and double the value of the knowledge, 15) managing tacit knowledge is a new challenge, 16) $\mathrm{KM}$ : to be a new eye of management in order to able to see what is hard to see before, 17) KM uses knowledge to create value to create maximum value, 18) The task of KM: individual tacit knowledge conversion to be organizational explicit knowledge, 19) The KM skill: how to dialogue and think together, 20) The replication of the best practical experience is a strategy to survive, while knowledge creation is the strategy to reach the future, 21) Close relationship and intangible capital can be a model as the basic to result maximum value, 22) The power has been shifted from capital owner to knowledge owner, 23) Get the right knowledge on the right time will save cost, 24) resistance to willing of listening can be from the culture of organization, 25) Personal reflection: a way to develop personal-mastery, 26) Group study to create horizontal feedback cycle, 27) Our mentally model to control how and what you can see or you can understand, 28) sharing culture will give benefit for sharing economy, 29) Sharing means double the use and benefit of collective intelligent, 30) Social media enables information sharing with more parties (could give positive or negative impact.

And there are 10 principles of $\mathrm{KM}$ in order to make the $\mathrm{KM}$ practice is more effective such as KM potential will become organizational energy when it is supported by the highest executive as leader enablers. Second, KM needs the foundation of learning organization. Third, KM needs knowledge sharing process. Fourth, KM needs mature workers. Fifth, KM is not computer system. Six, KM is more effective when collective organizational knowledge is stored and distributed. Seventh, KM implementation is started from the target of the organization (pull system). Eighth, KM is long life activity. Ninth, KM is expensive but there is no future for an organization that is not implementing $\mathrm{KM}$. Tenth, $\mathrm{KM}$ implementation is high level office politic. 


\section{The framework of KM from 4 types of models}

There are a lot of frameworks of KM with different relationship among the factors. Those are KM model Asian Productivity Organization (APO), European, NHS, and Global. However, the authors discuss more deeply only for Jann framework (the author's framework) and APO framework.

Jann model KM framework is parable with a two-floored house. The first floor shows the learning organization building. The second floor shows the KM building. The learning organization building is the interaction process among organization members. In order to gain effective and intensive organizational learning process, the members need learning habitats as well as useful facilities. The learning habitat becomes the foundation which is measured from trust each other and learning culture. The first pillar structure pictures the quality of human capital. The second pillar structure explains the importance of quality and quantity of the system and learning facility. The roof is the factors of learning discipline developed by Peter Senge (1990). Enabler of learning organization is a component influenced by the quality of the leader, enabler leader. Leaders in learning organization are responsible for building organization where people are continually expanding their capabilities to shape the futures.

The APO model KM framework has been revised four times. APO model has 6 layers: the statement of vision and mission of the organization. Second layer is acceleration step while the third layer contains the process of development and the conversion of organizational learning. The fourth layer is learning and innovating while the fifth layer is individual capability, team capability, organizational capability and also social capacity. The last layer is productivity, profitability, quality and organizational growth.

Each of models has different focus. An organization can choose any model to build a strategy of KM implementation by choosing one of the most suitable ones.

\section{How to measure organizational readiness on implementing $K M$}

Based on the organizational change, the diffusion of KM has three steps: readiness, adoption, and institutionalization. There are three approaches of KM implementation, practice approach, practice approach and best practice approach. The process approach contains knowledge codification and tacit to be explicit. The practice approach is more about assumption that most knowledge is tacit and the focus is developing the social environment. The best practice approach is to adapt the other method of organization which has been proven.

The methods to use the measurement of the organizational readiness are survey KM readiness, knowledge mapping and social networking analysis. The variables involved in the readiness measurement based on UTAUT model (unified theory of user acceptance for technology) are the $\mathrm{KM}$ infrastructure (organizational structure, its infrastructure and organizational culture), the performance (Fitriani at al., 2016) which is influenced by IT 
infrastructure and the organizational structure, and also the effort for learning KM process which is related with the organizational structure.

The knowledge mapping should be focusing on the two functions: strategic and tactical. The strategic function on the organization level is to draw the strategy of the business, to determine the capability of the organization and to identify the area of the KM focus. The other strategic function is cross division which is the knowledge mapping used on cross-functional. The tactical function is operational knowledge and tactic applied on the process, innovation and the relationship with the customers. There are three things revealed by knowledge mapping: contextual ad core knowledge, the information flowchart, and the critical skill of individual.

\section{The process of KM}

Basically, the process of KM contains 5 activities: identifying the knowledge, capturing and storing the knowledge, sharing and distributing the knowledge, applying the knowledge and also creation or developing knowledge.

There are three activities of identification process: looking for and finding the knowledge of the organisation, evaluating and analyzing the knowledge of the organisation, and knowledge mapping. The process of storing and looking for knowledge has at least two principles: it should be easy to access and easy to find, and it should be save from theft and lost.

The process of sharing and transferring is the primary and crucial step in KM process implementation which influences the effectiveness of the creation process. To support the effectiveness of the knowledge sharing, there are some skills should be owned by the workers: collaboration ability, publishing ability, able to keep connection, able to swap knowledge and able to build relation.

The process of knowledge application can be described as the process of product in supply-demand system in which there should be supplier party as well as the demand parties. In order to make sure there is knowledge flow, it is important to identify the factors that influence the effectiveness of the knowledge flow. Psychological factor (working environment) such as working motivation, willing to create renewal, willing to innovate and also many other factors such as knowledge supplier doesn't result suitable knowledge for the users, the workers get difficulty to access the knowledge center, the worker get difficulty to operate the information system because of unfriendly system and also the organization doesn't provide service for the workers who get the difficulty.

The creation process is introduced by Nonaka (1994) which has been applied by business organisations in Japan. This model is called SECI (socialization, externalization, combination and internalization). Socialisation is a transformation process from people to people (from tacit to tacit). Externalisation is transformation process from people to IT system (tacit to explicit), combination is transformation process from IT system to IT system (explicit to explicit) and internalization is transformation process from IT system to people (explicit to tacit). 


\section{The strategy to implement KM}

The step processes of KM implementation are the following: the preparation, context identification, KM habitat building, KM implementation and KM evaluation. For preparation step, the KM manager should prepare two working guidance: KM implementation should have goals and the strategy and initiative should be focused on the target or the goals.

There are 8 context indicator identifications which can be used to get description about the readiness of the organization to implement KM: the leader motivation level, the ability and the willing of the workers to learn, to think creative, to share knowledge and also the ability to identify knowledge needed. The latter three indicators are the ability to capture the knowledge and ability to use the knowledge in making decision and also the easiness to access the knowledge required.

To the step of building the learning habitat, there are 2 indicators to measure the KM habitat: mutual trust and learning culture. The higher the trust, the stronger the culture of study will be. As the habitat has been ready, the implementation is ready to be executed.

If the $\mathrm{KM}$ implementation has been done, the next step is to evaluate. In order to do this step, you need to discuss the concept of the working first: the indicators of the performance, measuring the performance, and also evaluate the KM.

There are two types of the KM implementation strategy: generic strategy and specific strategy. The generic strategies are motivation strategy, network strategy, knowledge supply strategy, analysis strategy, codification strategy, distribution strategy, growing demand strategy, use strategy and knowledge creation strategy. The types of more specific strategies are such as a strategy to lessen the cost and a strategy to increase the income.

At the end, the authors give a lot of examples of $\mathrm{KM}$ implementation which is not working because the assumption is not complete and the supporting factors are forgotten when implementing the KM.

\section{Reference}

Fitriani, W. R., Putra, A. G., Tanaya, D., Rochman, H. N., Cahyaningsih,E. and Sensuse, D. I. (2016). Assessing knowledge management implementation readiness in Faculty of Computer Science, Universitas Indonesia. 2016 International Conference on Advanced Computer Science and Information Systems (ICACSIS). 171-180, doi: 10.1109/ICACSIS.2016.7872743.

Tjakraatmadja, Jaan. H. \& Kristinawati, D. (2017). Strategi Implementasi Knowledge Management. Bandung: Penerbit ITB. 